\title{
Organic dairy farmers put more emphasis on production traits than conventional farmers
}

\author{
M. Slagboom, ${ }^{* 1}$ M. Kargo, ${ }^{*} \dagger$ D. Edwards, ${ }^{*}$ A. C. Sørensen, ${ }^{*}$ J. R. Thomasen, ${ }^{*} \ddagger$ and L. Hjort $\varnothing^{*} \dagger$ \\ *Department of Molecular Biology and Genetics, Center for Quantitative Genetics and Genomics, Aarhus University, DK-8830 Tjele, Denmark \\ †SEGES Cattle, DK-8200 Aarhus N, Denmark \\ ¥VikingGenetics, DK-8960 Assentoft, Denmark
}

\section{ABSTRACT}

The overall aim of this research was to characterize the preferences of Danish dairy farmers for improvements in breeding goal traits. The specific aims were (1) to investigate the presence of heterogeneity in farmers' preferences by means of cluster analysis, and (2) to associate these clusters with herd characteristics and production systems (organic or conventional). We established a web-based survey to characterize the preferences of farmers for improvements in 10 traits, by means of pairwise rankings. We also collected a considerable number of herd characteristics. Overall, 106 organic farmers and 290 conventional farmers answered the survey, all with Holstein cows. The most preferred trait improvement was cow fertility, and the least preferred was calving difficulty. By means of cluster analysis, we identified 4 distinct clusters of farmers and named them according to the trait improvements that were most preferred: Health and Fertility, Production and Udder Health, Survival, and Fertility and Production. Some herd characteristics differed between clusters; for example, farmers in the Survival cluster had twice the percentage of dead cows in their herds compared with the other clusters, and farmers that gave the highest ranking to cow and heifer fertility had the lowest conception rate in their herds. This finding suggests that farmers prefer to improve traits that are more problematic in their herd. The proportion of organic and conventional farmers also differed between clusters; we found a higher proportion of organic farmers in the production-based clusters. When we analyzed organic and conventional data separately, we found that organic farmers ranked production traits higher than conventional farmers. The herds of organic farmers had lower milk yields and lower disease incidences, which might explain the high ranking of milk produc-

\footnotetext{
Received April 22, 2016.

Accepted August 8, 2016.

${ }^{1}$ Corresponding author: margotslagboom@mbg.au.dk
}

tion and the low ranking of disease traits. This study shows that heterogeneity exists in farmers' preferences for improvements in breeding goal traits, that organic and conventional farmers differ in their preferences, and that herd characteristics can be linked to different farmer clusters. The results of this study could be used for the future development of breeding goals in Danish Holstein cows and for the development of customized total merit indices based on farmer preferences.

Key words: trait preference, organic farming, breeding goal, dairy cow

\section{INTRODUCTION}

In animal breeding, goals are defined to give relative importance to certain traits, usually based on economic weights (Groen et al., 1997). In Denmark, Finland, and Sweden, the Nordic Total Merit Index is based on common economic weights and is used as a breeding selection tool (Kargo et al., 2014). Breeding goals are defined for specific production systems and circumstances. To develop a breeding goal that farmers want to use, it is important to take account for farmers' objectives; a breeding goal that does not correspond to farmer preferences will make little sense (Nielsen et al., 2014). Such preferences can be defined using farmer choice experiments that use methods such as conjoint analysis (Tano et al., 2003), partial profile design (Nielsen and Amer, 2007), or pairwise rankings using preference-based tools such as 1000Minds (Byrne et al., 2012). Several studies have shown heterogeneity in farmers' preferences for breeding goal traits (Duguma et al., 2011, Ragkos and Abas, 2015), a finding that may be linked to different cattle production systems (Sy et al., 1997, Ouma et al., 2007). If farmer preferences are heterogeneous because of differences in production systems or farm or farmer characteristics, it might be necessary to create multiple breeding goals in a population (Nielsen and Amer, 2007).

Two production systems that are expected to influence farmer preferences for trait improvements are 
organic and conventional dairy farming. Organic farming has stronger regulations in terms of feed, outdoor access, and the use of antibiotics and anthelmintics than conventional farming. A lower use of concentrate feed causes lower milk production levels in most organic dairy systems (Bennedsgaard et al., 2003; Rosati and Aumaitre, 2004), but the price for organic dairy products is higher than that of conventional dairy products. In Denmark, organic farming is widely applied, and $10 \%$ of dairy farms are organic (Landbrug and Fødevarer, 2014). A previous study has shown that Swedish organic farmers place more emphasis on resistance to mastitis, parasites, and diseases, whereas conventional farmers emphasize higher milk production (Ahlman et al., 2014). Production level and farmer characteristics such as sex and age were found to affect improvement preferences for some traits, and the production system (organic or conventional) had the largest effect on farmer preferences (Ahlman et al., 2014).

Rather than analyzing farmer preferences in predefined groups (such as organic and conventional farmers), cluster analysis (CA) methods may be applied to identify groups of farmers with different preference profiles. These groups can be compared to see whether herd characteristics and production systems (organic or conventional) are associated with farmer preferences. Martin-Collado et al. (2015) showed that Australian farmers' trait preferences were heterogeneous and identified distinct groups by means of a CA. The groups they found, however, did not differ with respect to most of the herd characteristics measured in their study, suggesting that farmers' trait preferences were intrinsic to the farmers, rather than a result of measurable differences in characteristics. Cluster analysis can be a valuable tool to analyze farmer preferences.

The overall aim of this study was to characterize the preferences of Danish dairy farmers for breeding goal trait improvements. The specific aims were (1) to investigate the presence of heterogeneity in farmers' preferences by means of CA, and (2) to associate the clusters with herd characteristics and production systems (organic or conventional). We hypothesized that heterogeneity exists in farmers' preferences for trait improvements, and that it is related to the herd characteristics and production systems of the farmers.

\section{MATERIALS AND METHODS}

\section{Farmer Preference Study}

We established a web-based survey to characterize the preferences of dairy farmers for improvements in 10 traits. All traits, except for feed efficiency, were included in the current Nordic Total Merit index, but some were composite traits of multiple (indicator) traits. The survey used the online software 1000Minds (1000Minds Ltd., Dunedin, New Zealand), which applies the PAPRIKA method to minimize the number of questions (Hansen and Ombler, 2009). The farmers chose from 2 alternatives, formulated in such a way that the first trait would be improved and the second would remain at the same level, or vice versa (Figure 1). Farmers could also choose the option "they are equal." Improvements in the 2 traits represented equal monetary value, based on economic weights calculated for an organic system in Denmark (Kargo et al., 2015). The underlying monetary value was unknown to the farmer, because trait improvements were expressed in phenotypic units (such as $\mathrm{kg}$ of milk or \% pregnancy rate; see Table 1). Preferences were ranked accordingly. We sent the same survey to organic and conventional dairy farmers so that the results would be comparable. The correlation between the economic weights for an organic system and a conventional system was almost unity (Slagboom, 2015).

Farmers were also asked to answer a general questionnaire about characteristics of their herd, such as herd size, average milk yield, and housing system. In addition, we extracted data from the past year from the Danish Cattle Database for all farmers who completed the survey (Bundgaard and $\mathrm{H} \varnothing \mathbf{j}, 2000$ ). All recorded herd characteristics are described in Table 2, together with the average response for all items.

In April 2015, all Danish organic farmers with registered addresses in the cattle database $(\mathrm{n}=357)$, regardless of the breed they used, were contacted by ordinary mail to access the web-based survey. Farmers who had not answered, or had only partially completed the survey were later sent an e-mail, contacted by phone, or both. In August 2015, almost all $(\mathrm{n} \approx 3,000)$ conventional farmers were contacted by e-mail to access the survey, and a random sample of these farmers were later also contacted by phone to minimize bias. The survey results for the organic dairy farmers were not published before the survey of the conventional dairy farmers was finished. The general questionnaire was linked to the preference survey based on the herd number that farmers filled in. Not all farmers filled in both the general questionnaire and the preference survey, and some herd numbers did not match. All farmers who completed the preference survey were included in the analysis. In this paper, only the results from Holstein data are presented.

\section{Statistical Analysis}

The part-worth utilities were translated into trait ranks by 1000Minds, where the most preferred trait 


\section{0 minds $^{\circ}$}

\section{Preferences survey}

Please reveal your preferences by answering the following questions.

\section{Question \# 1}

Which of these two alternatives do you prefer?

(given they're identical in all other respects)
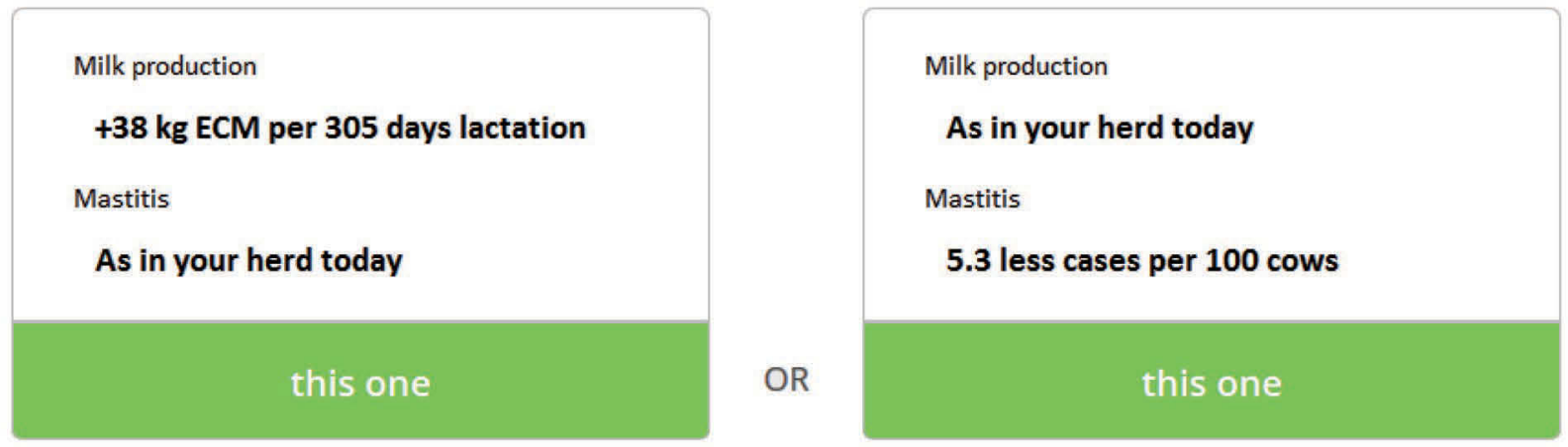

they are equal

$0 \%$ complete

Larger font for questions (easier to read)

Figure 1. Example of a question in the preference survey. Color version available online.

was ranked 1 and the least preferred trait was ranked 10. We used these trait ranks to produce descriptive statistics for the survey outcomes.
To analyze differences in mean trait ranks, a Friedman test was performed (Friedman, 1937). This test accounts for dependency and non-normality in the data

Table 1. Breeding goal trait improvements included in the preference survey

\begin{tabular}{|c|c|c|c|}
\hline \multirow{2}{*}{$\frac{\text { Trait }}{\text { Cow fertility }}$} & \multirow{2}{*}{$\begin{array}{l}\text { Description } \\
\text { Pregnancy rate in cows }\end{array}$} & \multicolumn{2}{|c|}{ Improvement presented in the survey } \\
\hline & & 39 & Pregnancies per 100 inseminations \\
\hline Heifer fertility & Pregnancy rate in heifers & 11 & Pregnancies per 100 inseminations \\
\hline Calving difficulty & A difficult calving & -8.2 & Cases per 100 cow-years ${ }^{1}$ \\
\hline Calf mortality & Death within 15 mo after birth & -12 & $\begin{array}{l}\text { Dead heifers and heifer calves per } 100 \text { cow- } \\
\text { years }{ }^{1}\end{array}$ \\
\hline Cow mortality & Mortality and involuntary culling & -1.8 & Cases per 100 cow-years ${ }^{1}$ \\
\hline Hoof and leg diseases & Hoof and leg diseases & -13.5 & Cases per 100 cow-years ${ }^{1}$ \\
\hline Mastitis & Clinical mastitis & -5.3 & Cases per 100 cow-years ${ }^{1}$ \\
\hline Other diseases & Reproductive, digestive, and metabolic diseases & -10.1 & Cases per 100 cow-years ${ }^{1}$ \\
\hline Milk production ${ }^{2}$ & 305-d ECM yield & 38 & $\mathrm{~kg}$ of ECM per $305^{\circ} \mathrm{d}$ of lactation \\
\hline Feed efficiency & ECM yield per feed unit & 0.01 & $\mathrm{~kg}$ of ECM per feed unit \\
\hline
\end{tabular}

\footnotetext{
${ }^{1}$ The number of cow-years equals the number of feeding days per year (for all the cows in a herd) divided by 365 .
}

${ }^{2}$ Test-day yield of ECM $(\mathrm{kg})$ was calculated as $[\mathrm{kg}$ of milk $\times(383 \times$ fat $\%+242 \times$ protein $\%+780.8)] / 3,140$. 
Table 2. Herd characteristics for all farmers that inseminated some or all of their cows with Holstein semen

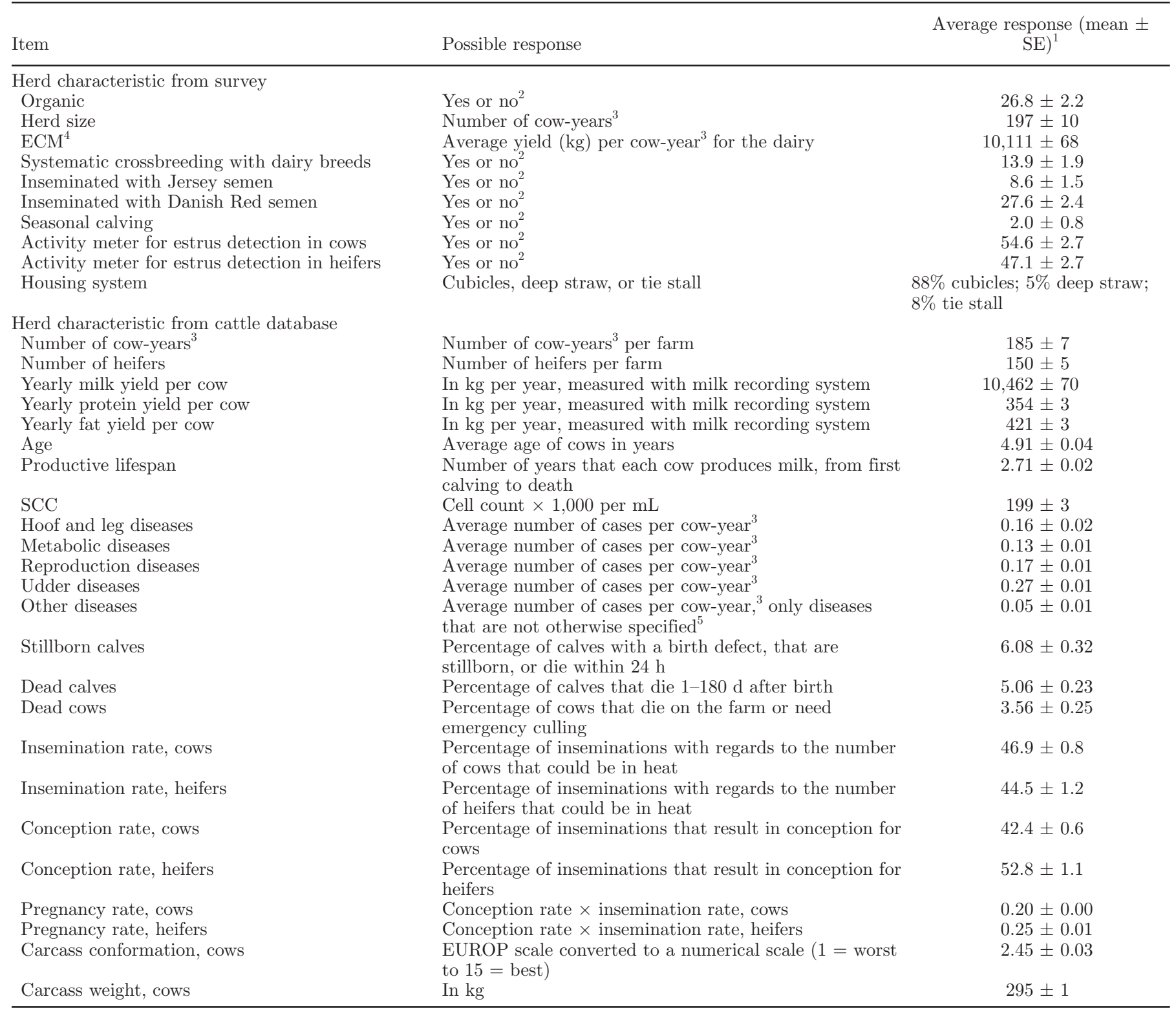

\footnotetext{
${ }^{1}$ The number of respondents ranged from 314 to 396 per characteristic.

${ }^{2}$ Farmers who answered yes compared with all farmers who answered this question.

${ }^{3}$ The number of cow-years equals the number of feeding days per year (for all the cows in a herd) divided by 365 .

${ }^{4}$ Test-day yield of ECM $(\mathrm{kg})$ was calculated as $[\mathrm{kg}$ of milk $\times(383 \times$ fat $\%+242 \times$ protein $\%+780.8)] / 3,140$.

${ }^{5}$ The herd characteristic "Other diseases" was not the same as the trait "Other diseases," presented to farmers in the survey. Metabolic and reproductive diseases were part of the trait but not part of the herd characteristic (because they were recorded separately).
}

by using a 2-factor unreplicated design, in which each farmer (the first factor) ranks each trait (the second factor). A significant result $(P<0.05)$ on the Friedman test meant that at least one of the trait means was different from the other traits, and then a post hoc test, Nemenyi, was performed to test pairwise differences (Sachs, 2013). Both tests were done using the
Pairwise Multiple Comparison of Mean Ranks Package in R statistical software (Pohlert, 2015).

We conducted a principal component analysis in $\mathrm{R}$ (Husson et al., 2010). The results did not suggest that a dimension reduction would be appropriate. Therefore, we decided to perform a Ward's hierarchical cluster analysis on the unreduced data. The optimal number 
of clusters was based on gain of within-group inertia criterion. All characteristics of the clusters, from the general questionnaire and the cattle database, were tested for homogeneity across clusters using a Kruskal-Wallis test. A significant result $(P<0.05)$ of the Kruskal-Wallis test for a characteristic meant that at least 1 of the cluster means differed from the others. Subsequently, we performed Dunn's post hoc test for pairwise differences (Dunn, 1964). We adjusted the test using the Holm method, which controls the family-wise error rate (Holm, 1979).

These analyses were first performed for all data together and then separately for data from organic and conventional farmers. Descriptive statistics were also produced separately for organic and conventional farmers, and differences between the 2 production systems were analyzed with a Kruskal-Wallis test.

\section{RESULTS}

The response rate for the preference survey was $48 \%$ for organic farmers and $13 \%$ for conventional farmers for the 3 major dairy breeds in Denmark. In this study, we used the answers from 396 farmers that inseminated some or all of their cows with Holstein semen (290 conventional and 106 organic herds).

\section{Preferences for Trait Improvements for All Farmers}

The ranks for all 10 traits and the differences between the trait ranks are shown in Figure 2. The highest rank was given to an improvement in cow fertility [4.29 \pm 0.13 (mean $\pm \mathrm{SE}$ )], followed by improvements in hoof and leg diseases, mastitis, and milk production, and the lowest rank was given to improvements in calving difficulty (7.27). The remaining traits were all ranked intermediately, and their mean ranks did not significantly differ from each other. Standard deviations for trait ranks ranged from 2.43 to 3.09 .

Different Farmer Clusters. We found 4 clusters by means of CA. We described and classified the clusters according to their most and least preferred trait improvements compared with other clusters and compared with trait ranks for all farmers together (Figure

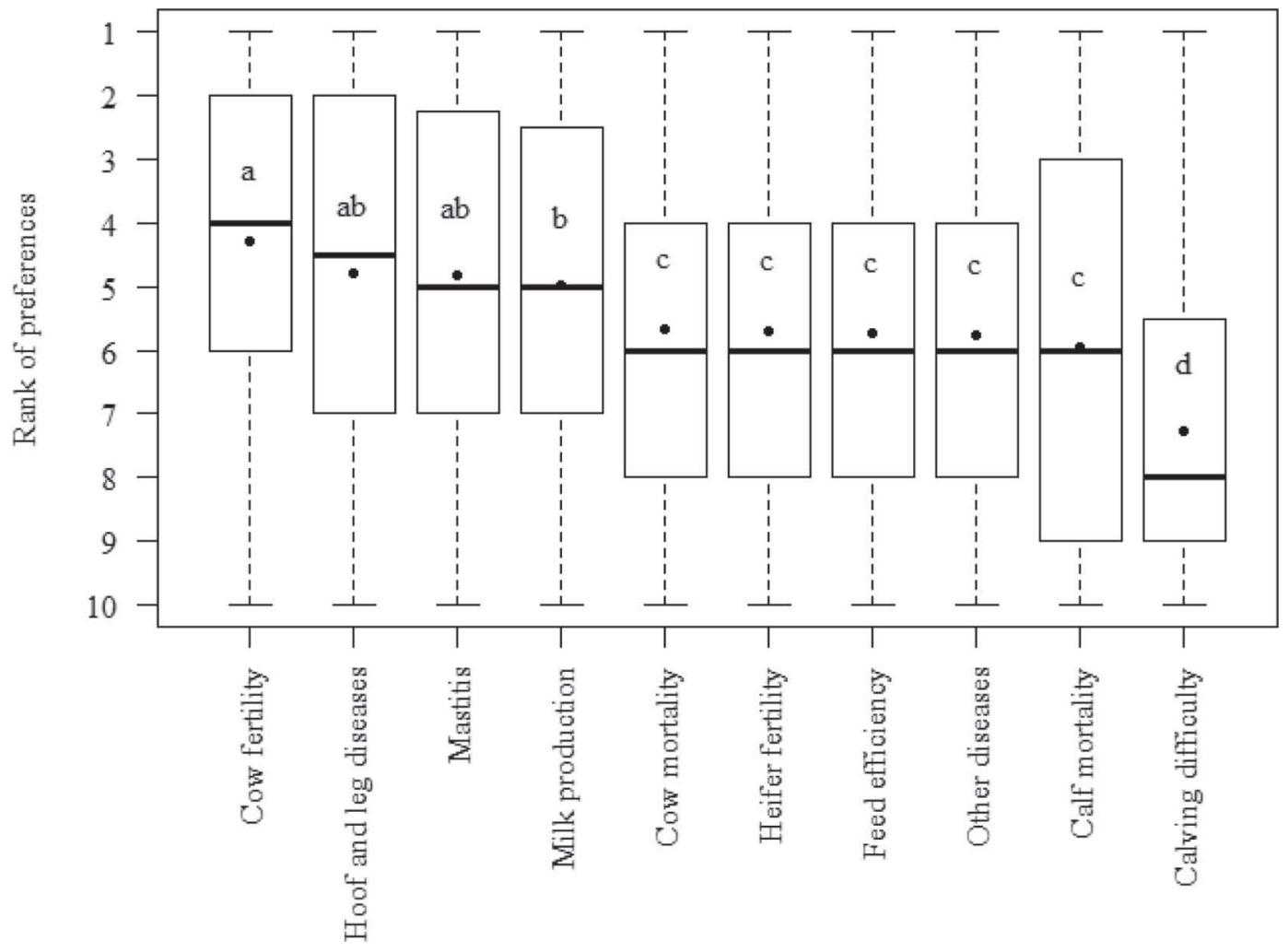

Figure 2. Boxplot of trait ranks for the 10 traits evaluated in the survey. Means with different letters differ $(P<0.05)$ according to a Nemenyi post hoc test. The bottom and the top of the box represent the first and the third quartile, the line in the box represents the median, and the dot represents the mean. The whiskers represent the minimum and maximum answer for each trait. 
- All farmers

$\square$ Health and Fertility

$\square$ Production and Udder Health

\Survival

四Fertility and Production

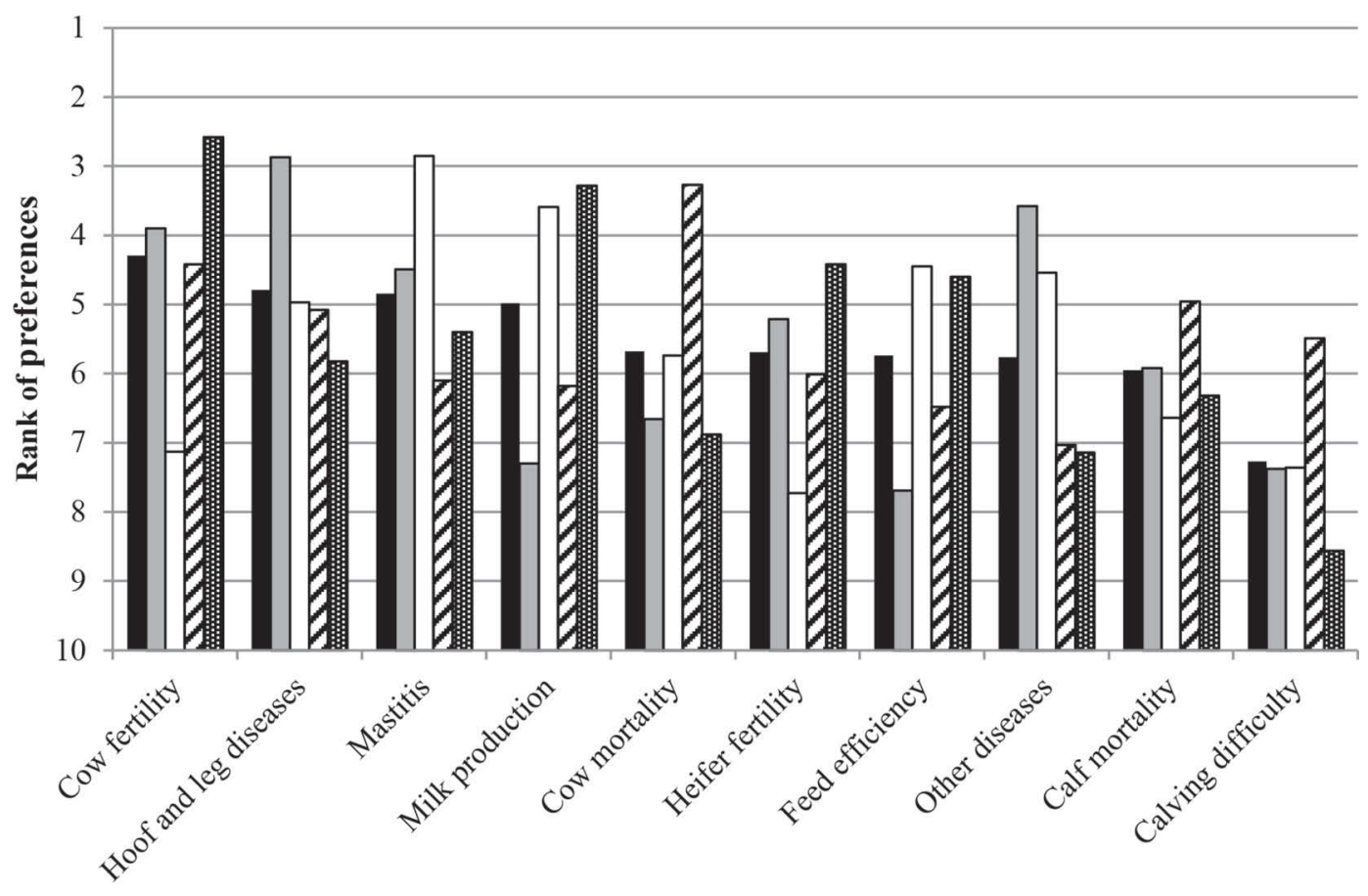

Trait

Figure 3. Mean trait ranks for all farmers together and per cluster. The number of farmers in the Health and Fertility cluster was 89 , in Production and Udder Health was 83, in Survival was 100, and in Fertility and Production was 124.

3). All mean trait ranks differed $(P<0.05)$ according to a Kruskal-Wallis test, implying that at least one of the clusters had a different mean.

Farmers in the first cluster, Health and Fertility, gave most preference to improvements in traits related to diseases and fertility. In particular, hoof and leg diseases and other diseases were ranked much higher in this cluster compared with their overall rankings. Farmers in this cluster gave least preference to production traits such as milk production and feed efficiency.

Farmers in the second cluster, Production and Udder Health, were mostly oriented toward improving production traits and mastitis. Improvements in fertility traits were the least preferred.

Farmers in the third cluster, Survival, placed the most emphasis on calf and cow mortality. Compared with all farmers together, these farmers gave a much higher rank to calving difficulty. Other diseases and production traits were least preferred by these farmers.
Farmers in the fourth cluster, Fertility and Production, gave the highest rankings to fertility and production traits. Calving difficulty, other diseases, and hoof and leg diseases were ranked lowest compared to all farmers together. These farmers gave the highest rank of all farmers to cow and heifer fertility and to milk production.

Associations with Production System. We found a difference in the proportion of organic farmers between clusters (Table 3). Farmer clusters that were more production-based (Production and Udder Health and Fertility and Production) had the highest percentage of organic farmers, whereas the Survival and Health and Fertility clusters had a higher percentage of conventional farmers. When comparing mean trait ranks between conventional and organic farmers, we found that calf mortality and milk production were ranked higher by organic farmers $(P<0.001$ and $P=0.02$, respectively) and calving difficulty, cow mortality, and 
Table 3. Trait ranking $(1=$ highest, $10=$ lowest), and herd characteristics (mean $\pm \mathrm{SE})$ per farmer cluster; only herd characteristics with a difference between clusters $(P<0.10)$ are shown

Cluster

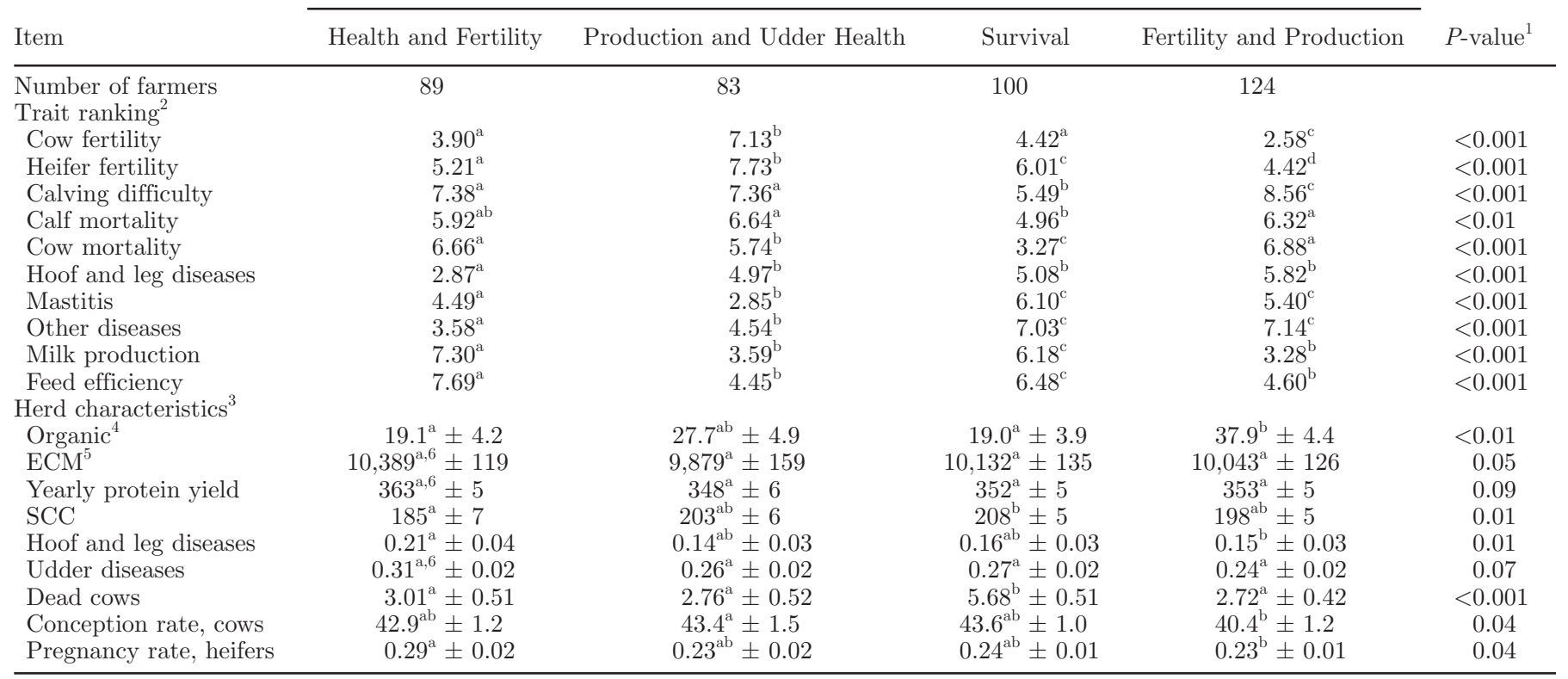

${ }^{\mathrm{a}-\mathrm{d}}$ Means within a row with different superscripts differ $(P<0.05)$ according to Dunn's test for multiple comparisons.

${ }^{1}$ Result of Kruskal-Wallis test with the null hypothesis "all cluster means are equal."

${ }^{2}$ Standard errors of trait rankings were in the range of $0.14-0.35$.

${ }^{3}$ Descriptions and average response per herd characteristic can be found in Table 2 .

${ }^{4}$ Organic farmers among the survey respondents.

${ }^{5}$ Test-day yield of ECM $(\mathrm{kg})$ was calculated as $[\mathrm{kg}$ of milk $\times(383 \times$ fat $\%+242 \times$ protein $\%+780.8)] / 3,140$.

${ }^{6}$ Due to an adjustment of $P$-values to correct for the family-wise error rate, it may be that pairwise differences cannot be found by the Dunn's test, even though the Kruskal-Wallis test showed that at least one of the cluster means was different $(P<0.05)$.

hoof and leg diseases were ranked lower $(P=0.03, P<$ 0.01 , and $P<0.01$ ) according to a Kruskal-Wallis test. A large number of herd characteristics differed between organic and conventional farmers (Table 4). Average yields, ECM, disease incidences, and the percentage of dead cows were lower in organic herds; the percentage of dead calves was higher in organic herds, as well as the average age of the cows and their productive lifespan.

Associations with Herd Characteristics. Some herd characteristics differed significantly between clusters (Table 3). Farmers in the Survival cluster had a higher percentage of dead cows in their herds than the other clusters $(P<0.001)$. These herds also had a higher SCC. Herds of farmers that gave the highest rank to cow and heifer fertility, in the Fertility and Production cluster, had the lowest conception rate for cows. Farmers in the Health and Fertility cluster ranked hoof and leg diseases highest and had the highest incidence of hoof and leg diseases. This cluster also had the highest incidence of udder diseases, but the difference between clusters was not significant $(P=0.07)$. The productionbased clusters had the lowest yearly ECM yield and yearly protein yield, and the overall Kruskal-Wallis test showed this tendency $(P=0.05$ and $P=0.09$, respectively). However, pairwise differences between clusters were not significant.

\section{Conventional Farmers}

When analyzing the conventional farmers $(\mathrm{n}=290)$ separately, the trait ranks were very similar to the trait ranks for all farmers together. We found 3 clusters using a CA. All mean trait ranks differed $(P<0.05)$ according to a Kruskal-Wallis test. The mean ranks of trait improvements are shown in Figure 4 for all conventional farmers and per conventional farmer cluster. The first cluster we found, Health, consisted of farmers that ranked all disease traits highest, but unlike Health and Fertility from the CA for all farmers together, these farmers did not rank fertility traits very high. The second and third clusters for conventional farmers contained farmers that ranked traits in the same way as the Survival and Fertility and Production clusters from the analysis of all farmers together.

When comparing herd characteristics, we found differences between clusters (Table 5). As in the overall 
Table 4. Average herd characteristics for organic and conventional farmers who participated in the survey (n $=106$ and $\mathrm{n}=290$, respectively); only herd characteristics with a difference between the 2 production systems $(P<0.10)$ are shown

\begin{tabular}{lccc}
\hline Herd characteristic $^{1}$ & Organic & Conventional & $P_{\text {-value }}{ }^{2}$ \\
\hline ECM $^{3}$ & $9,314 \pm 118$ & $10,419 \pm 73$ & $<0.001$ \\
Systematic crossbreeding with dairy breeds & $23.2 \pm 4.4$ & $10.4 \pm 1.9$ & $<0.01$ \\
Inseminated with Danish Red semen & $37.1 \pm 4.9$ & $23.9 \pm 2.7$ & 0.01 \\
Activity meter for estrus detection in cows & $66.3 \pm 4.9$ & $50.2 \pm 3.2$ & $<0.01$ \\
Yearly milk yield per cow & $9,736 \pm 122$ & $10,751 \pm 78$ & $<0.001$ \\
Yearly protein yield per cow & $327 \pm 4$ & $365 \pm 3$ & $<0.001$ \\
Yearly fat yield per cow & $392 \pm 5$ & $432 \pm 3$ & $<0.001$ \\
Age & $5.09 \pm 0.05$ & $4.83 \pm 0.05$ & $<0.001$ \\
Productive lifespan & $2.86 \pm 0.04$ & $2.65 \pm 0.03$ & $<0.001$ \\
SCC & $220 \pm 6$ & $191 \pm 3$ & $<0.001$ \\
Hoof and leg diseases & $0.07 \pm 0.02$ & $0.20 \pm 0.02$ & $<0.001$ \\
Metabolic diseases & $0.09 \pm 0.01$ & $0.14 \pm 0.01$ & $<0.001$ \\
Reproduction diseases & $0.10 \pm 0.01$ & $0.20 \pm 0.01$ & $<0.001$ \\
Udder diseases & $0.19 \pm 0.01$ & $0.30 \pm 0.01$ & $<0.001$ \\
Dead calves & $5.98 \pm 0.45$ & $4.70 \pm 0.26$ & $<0.01$ \\
Dead cows & $1.63 \pm 0.36$ & $4.32 \pm 0.31$ & $<0.001$ \\
Insemination rate, heifers & $39.0 \pm 2.4$ & $46.5 \pm 1.4$ & $<0.01$ \\
Pregnancy rate, heifers & $0.20 \pm 0.02$ & $0.26 \pm 0.01$ & $<0.01$ \\
Carcass conformation, cows & $2.32 \pm 0.04$ & $2.50 \pm 0.03$ & $<0.01$ \\
Carcass weight, cows & $289 \pm 2$ & $297 \pm 2$ & $<0.01$ \\
\hline
\end{tabular}

${ }^{1}$ Descriptions and average response per herd characteristic can be found in Table 2 .

${ }^{2}$ Result of Kruskal-Wallis test with the null hypothesis "both means are equal."

${ }^{3}$ Test-day yield of ECM $(\mathrm{kg})$ was calculated as $[\mathrm{kg}$ of milk $\times(383 \times$ fat $\%+242 \times$ protein $\%+780.8)] / 3,140$.

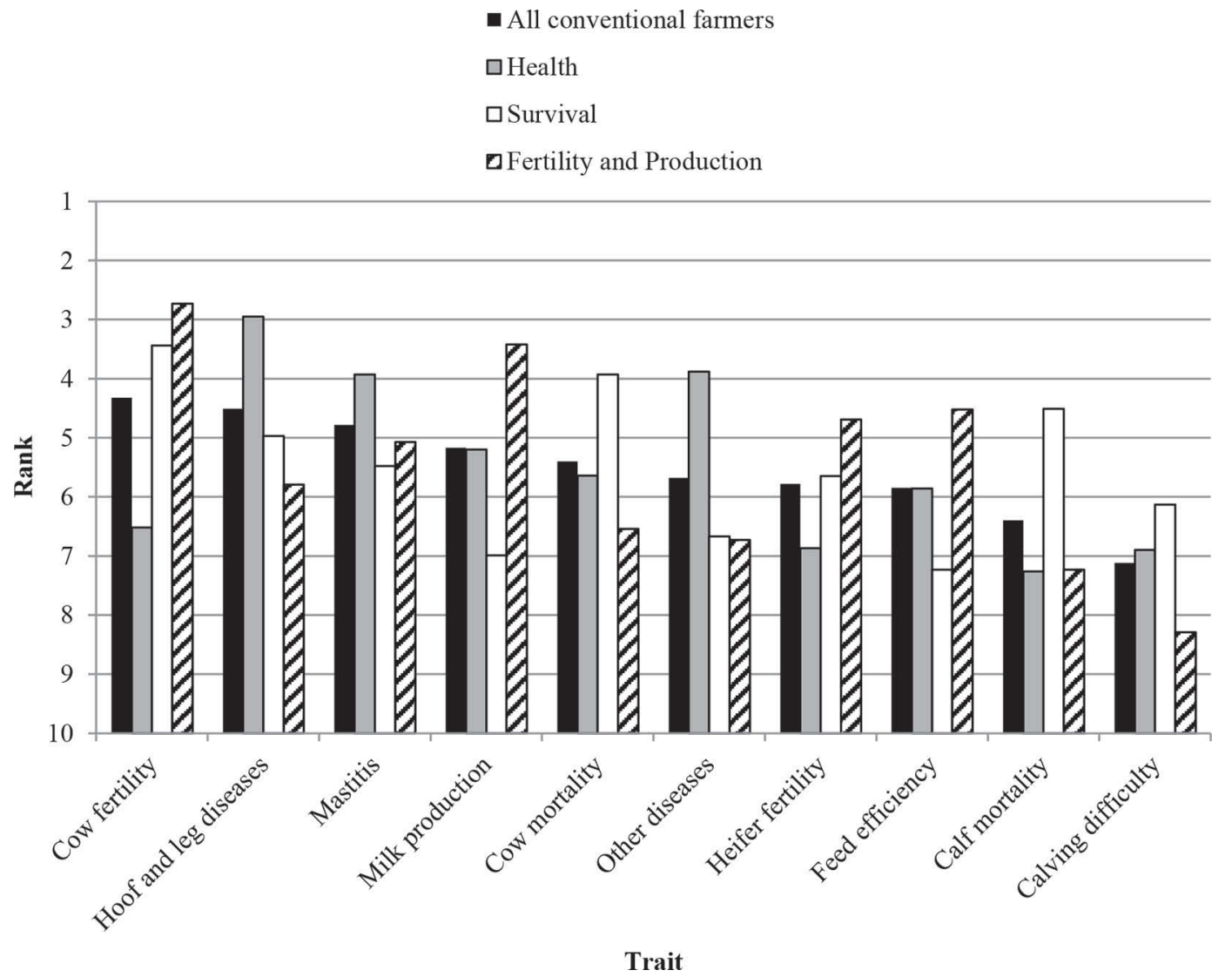

Figure 4. Mean trait ranks for conventional farmers together and per cluster of conventional farmers. The number of farmers in the Health cluster was 105, in Survival was 90, and in Fertility and Production was 95. 
analysis, the Survival cluster again contained herds that had a higher percentage of dead cows.

\section{Organic Farmers}

Organic farmers $(\mathrm{n}=106)$ mostly preferred improvements in cow fertility (rank $4.21 \pm 0.26$ ), followed by milk production and calf mortality; improvements in calving difficulty were least preferred (rank 7.69). We found 3 clusters based on organic farmers' preferences for trait improvements (Figure 5). All mean trait ranks differed $(P<0.05)$, but we did not identify any differences in herd characteristics between the clusters. The first cluster of organic farmers, Robustness, contained farmers that were mostly oriented toward improving mortality and disease traits; these farmers ranked production traits very low. The second and third clusters of organic farmers were similar to the Production and Udder Health and Fertility and Production clusters from the analysis of all farmers together.

\section{DISCUSSION}

The present study characterized the preferences of Danish dairy farmers for improvements in breeding goal traits and associated these preferences with herd characteristics and production systems (organic or conventional). The clusters found in this study differed in trait rankings, and in the proportion of organic and conventional farmers. When analyzing the combined data from all farmers, we found that farmer clusters that were more production-based contained a higher percentage of organic farmers. Organic farmers also ranked milk production higher than conventional farmers. The analysis for organic farmers separately found 2 production-based clusters, whereas the analysis for conventional farmers found only 1 production-based cluster. The reason for this might be that the average milk yield is lower in organic herds than in conventional herds and that the price for organic milk is higher. On the other hand, disease incidences are lower in organic herds, so farmers might rank those traits lower simply because they are less of a problem in their herd. If the need to improve disease-related traits is lower, a farmer can easily choose to improve milk yield, because higher yield can directly improve farmer income.

Ahlman et al. (2014) found that Swedish organic farmers tended to value milk production lower and health traits higher compared with conventional farmers. However, the design of our survey was completely different from their survey. Where we used pairwise rankings based on the economic values of traits, they used several different techniques including giving custom weights to the 5 most preferred traits by the farmers. Farmers were thus able to see the consequences of their preference on genetic gain in the individual traits, something that was not possible in our design. The differences in the answers given in Sweden and Denmark may to a large extent relate to the time perspective, meaning that the farmer preferences given in our result had a shorter time horizon than the preferences in the Swedish survey, because Swedish farmers knew some (but not all) of the long-term consequences before answering the questionnaire. On the other hand, our survey was based on economic weights derived from a simulation study of an average organic farm in Denmark, so the choices of farmers might be more realistic. Also, the high number of respondents for our survey, especially for organic farmers, gave us a reliable estimate of farmers' preferences. Thus, production system can be linked to farmers' preferences, and organic farmers ranked production traits higher compared with conventional farmers.

Besides production system, some other herd characteristics also differed significantly between clusters. In this study, we recorded a large number of herd char-

Table 5. Average herd characteristics per cluster of conventional farmers; only herd characteristics with a difference between clusters $(P<0.10)$ are shown

\begin{tabular}{|c|c|c|c|c|}
\hline \multirow[b]{2}{*}{ Item } & \multicolumn{3}{|c|}{ Cluster } & \multirow[b]{2}{*}{$P$-value ${ }^{1}$} \\
\hline & Health & Survival & Fertility and Production & \\
\hline $\begin{array}{l}\text { Number of farmers } \\
\text { Herd characteristic }\end{array}$ & 105 & 90 & 95 & \\
\hline Yearly milk yield & $10,831^{\mathrm{a}} \pm 111$ & $10,508^{\mathrm{a}} \pm 164$ & $10,913^{\mathrm{a}} \pm 128$ & 0.04 \\
\hline Yearly protein yield & $368^{\mathrm{a}} \pm 4$ & $356^{\mathrm{a}} \pm 6$ & $371^{\mathrm{a}} \pm 5$ & 0.04 \\
\hline Yearly fat yield & $436^{\mathrm{a}} \pm 4$ & $423^{\mathrm{a}} \pm 6$ & $436^{\mathrm{a}} \pm 5$ & 0.04 \\
\hline Productive lifespan & $2.70^{\mathrm{a}} \pm 0.05$ & $2.69^{\mathrm{a}} \pm 0.05$ & $2.55^{\mathrm{a}} \pm 0.05$ & 0.05 \\
\hline Dead cows & $3.68^{\mathrm{a}} \pm 0.50$ & $6.16^{\mathrm{b}} \pm 0.53$ & $3.13^{\mathrm{a}} \pm 0.51$ & $<0.001$ \\
\hline
\end{tabular}

${ }^{\mathrm{a}, \mathrm{b}}$ Means within a row with different superscripts differ $(P<0.05)$ according to Dunn's test for multiple comparisons.

${ }^{1}$ Result of Kruskal-Wallis test with the null hypothesis "all cluster means are equal."

${ }^{2}$ Descriptions and average response per herd characteristic can be found in Table 2. 


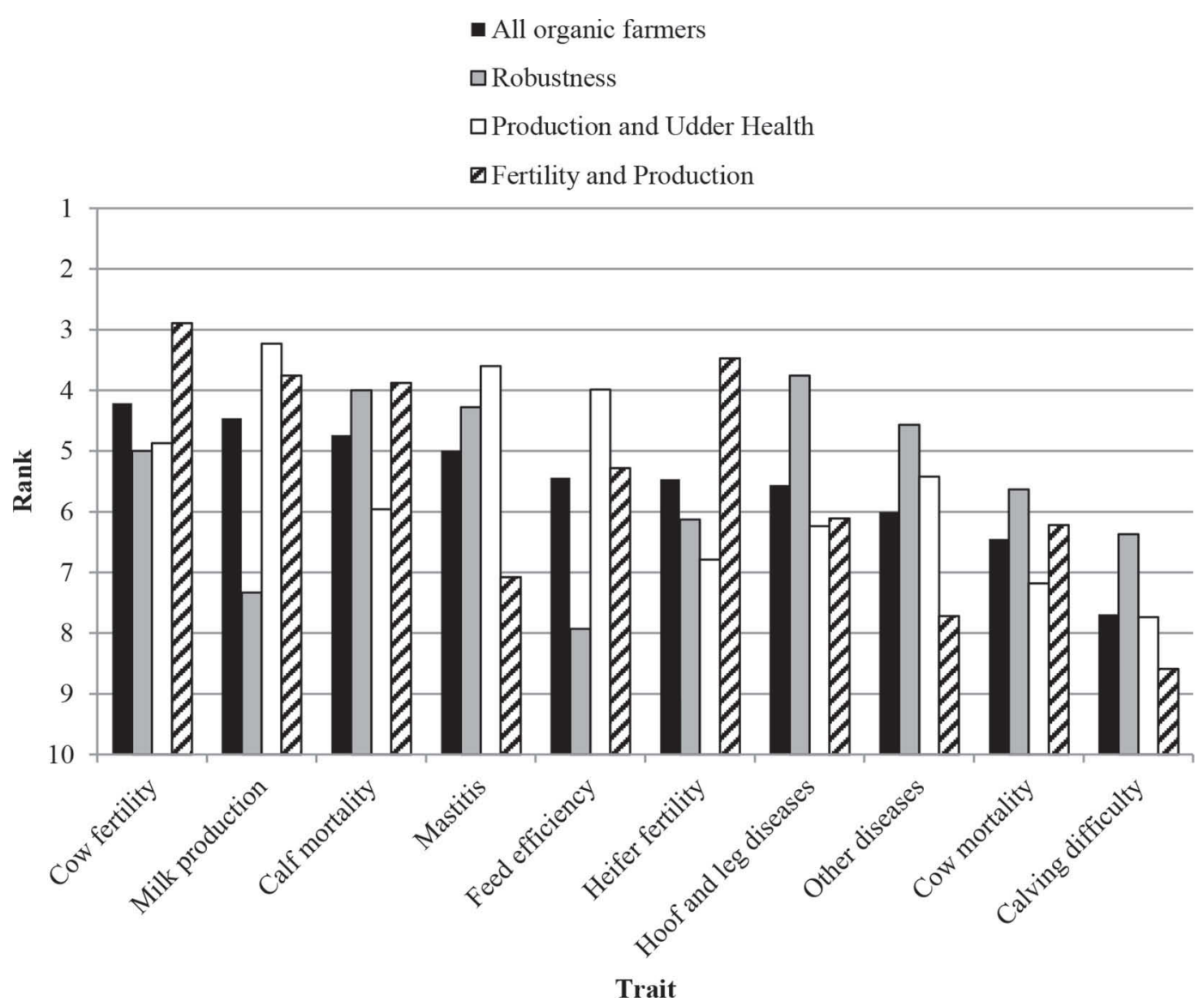

Figure 5. Mean trait ranks for organic farmers together and per cluster of organic farmers. The number of farmers in the Robustness cluster was 27, in Production and Udder Health was 42, and in Fertility and Production was 37.

acteristics and compared them between clusters. The herd characteristics that differed significantly between clusters indicated that farmers ranked traits more highly when they were related to problems they had in their herd. The clearest example of this was that farmers who ranked mortality traits highest had the highest percentage of dead cows in their herds. Another example is that farmers who gave the highest rank to cow and heifer fertility had the lowest conception rate in their herds. When we compared organic farmers with conventional farmers, we also found that farmers want to improve traits that are more problematic in their herds. Because many herd characteristics differed between organic and conventional farmers, production system can be seen as a predictor of certain herd characteristics, such as yields and disease incidences (Table 4). This suggests that production system is more an indicator of certain herd characteristics related to farmers' preferences, rather than being an indicator of preferences directly. Martin-Collado et al. (2015) found that the farm and farmer characteristics measured in their study did not differ between clusters, except for farmer age. Therefore, they suggested that farmers' preferences for trait improvements were intrinsic to farmers. The results from this study suggest that farmers choose to improve traits they have a problem with in their herd.

In this study, we found heterogeneity in farmer preferences, corroborating the findings of previous studies (Duguma et al., 2011; Ragkos and Abas, 2015). By means of CA, we found distinct clusters that differed in their ranking of all 10 traits surveyed, showing the diversity of the clusters. We decided to use all 10 principal components for the $\mathrm{CA}$, because the results did not show that a reduced number of principal components would explain a sufficient proportion of the variability. Thus, we analyzed all variability in farmers' preferences, and we found some farmers that were more production-focused and some that were more functionality-focused. But instead of being either production- or functionality-focused, farmers distinguished between different functional traits, ranking groups of health-related, survival, and fertility traits in roughly the same way. Mastitis was a special case that some- 
times seemed more linked to production traits than to functional traits. This could be because farmers have to discard the milk when a cow is being treated for mastitis. Martin-Collado et al. (2015) studied Australian farmers' preferences for trait improvements and found comparable results. They performed a CA of the first 5 principal components, which accounted for only $55.5 \%$ of the variability. The clusters they found contained farmers that were production-focused, functionalityfocused, or type-focused. Thus, farmers' preferences for breeding goal traits are not homogeneous, but clusters of farmers with different preference profiles can be identified.

When using predefined improvements in traits, some bias in the results may occur. The improvements for traits in this study were based on economic weights simulated for an organic system in Denmark. Conventional farmers answered the survey based on these economic weights, but because the correlation between economic weights calculated for a conventional system and for an organic system was almost unity, it was unlikely that there was bias because of this. The trait improvements compared in the survey were all equal to 100 Danish Krone in monetary values; we believe the pairwise rankings provided a good representation of farmers' preferences. However, the use of trait improvements based on simulated economic weights might create a bias when the absolute value of 1 of the improvements is very high, and this was the case for the value of cow fertility (39 pregnancies per 100 inseminations). This result may have caused a bias in farmers being more inclined to choose for cow fertility, and cow fertility was the most preferred trait for all farmers together. However, the mean rank of cow fertility did not significantly differ from that of hoof and leg diseases or mastitis (Figure 2). The different farmer clusters also showed great variation in ranking of cow fertility, and some farmers still gave a low preference to this trait (Table 3), despite the high improvement presented in the survey. Therefore, the potential bias created by using this method is unlikely to be very high.

The number of respondents in the survey was quite high, but a potential bias might have been present nonetheless. Several farmers filled in the general questionnaire but did not proceed to the preference survey. Through personal communication with a group of farmers after the survey, some farmers said the survey took too long to finish. This could be a reason why farmers did not fill in both the general questionnaire and the preference survey. A higher proportion of organic farmers were contacted by phone than conventional farmers, so the proportion of organic respondents was higher relative to the proportion of organic farmers in Denmark. This might have caused the trait rankings for all farmers to shift more toward organic farmers' preferences, rather than being representative of the whole farmer population in Denmark. However, by analyzing the organic and conventional farmers separately, we had a good perspective on farmer preferences per production system. The survey was intended to be anonymous, but because the general questionnaire and the preference survey had to be linked somehow, we asked farmers to fill in their herd number. However, respondents were told that the herd number would be used only to link the general questionnaire with the preference survey. In this way, we feel that the potential for bias was minimized.

The results of this study can be used to develop total merit indices for different farmer types, either as customized indices or as indices for different lines at the population level. This can be done in different ways. The first method is by using the weights based directly on farmer preferences from the different clusters, in monetary values. The software we used (1000Minds) also provides this type of data. The ranking data used for the definition of farmer clusters are valuable for understanding farmer preferences, but cannot be used directly to calculate the relative weightings of traits. The second method is by changing the assumptions in the model that derive economic weights so that the assumptions correspond to phenotypic levels within each cluster. Irrespective of which method is chosen, the result is increased ownership of the breeding goal. Given the assumed short-term perspective of the answers from the survey, we suggest that breeding goals derived from farmer preferences be used as customized indices. For breeding goals to be used at the population level, the long-term effects on genetic gain for all traits involved must be known.

\section{CONCLUSIONS}

This study showed that organic farmers prefer more improvements in production traits compared with conventional farmers. Heterogeneity exists in farmers' preferences, and we found specific clusters of farmers based on these preferences. Herd characteristics also differed between clusters, implying that farmers prefer to improve traits that are more problematic in their herd.

\section{ACKNOWLEDGMENTS}

The project SOBcows is part of the Organic RDD 2 program, which is coordinated by the International Centre for Research in Organic Food Systems (ICROFS, Tjele, Denmark). It has received grants from the Green Growth and Development program (GUDP) under the 
Danish Ministry of Food, Agriculture and Fisheries (Copenhagen).

\section{REFERENCES}

Ahlman, T., M. Ljung, L. Rydhmer, H. Röcklinsberg, E. Strandberg, and A. Wallenbeck. 2014. Differences in preferences for breeding traits between organic and conventional dairy producers in Sweden. Livest. Sci. 162:5-14. http://dx.doi.org/10.1016/j. livsci.2013.12.014.

Bennedsgaard, T. W., S. M. Thamsborg, M. Vaarst, and C. Enevoldsen. 2003. Eleven years of organic dairy production in Denmark: Herd health and production related to time of conversion and compared to conventional production. Livest. Prod. Sci. 80:121-131. http://dx.doi.org/10.1016/S0301-6226(02)00312-3.

Bundgaard, E., and S. Høj. 2000. Direct Access to the Cattle Database with Livestock Registration. Annual Report 1999. National Committee on Danish Cattle Husbandry, Aarhus, Denmark.

Byrne, T. J., P. R. Amer, P. F. Fennessy, P. Hansen, and B. W Wickham. 2012. A preference-based approach to deriving breeding objectives: Applied to sheep breeding. Animal 6:778-788. http:// dx.doi.org/10.1017/S1751731111002060.

Duguma, G., T. Mirkena, A. Haile, A. M. Okeyo, M. Tibbo, B. Rischkowsky, J. Sölkner, and M. Wurzinger. 2011. Identification of smallholder farmers and pastoralists' preferences for sheep breeding traits: Choice model approach. Animal 5:1984-1992. http:// dx.doi.org/10.1017/S1751731111001029.

Dunn, O. J. 1964. Multiple comparisons using rank sums. Technometrics 6:241-252. http://dx.doi.org/10.1080/00401706.1964.1049 0181.

Friedman, M. 1937. The use of ranks to avoid the assumption of normality implicit in the analysis of variance. J. Am. Stat. Assoc. 32:675-701. http://dx.doi.org/10.1080/01621459.1937.10503522.

Groen, A. F., T. Steine, J.-J. Colleau, J. Pedersen, J. Pribyl, and N. Reinsch. 1997. Economic values in dairy cattle breeding, with special reference to functional traits. Report of an EAAP-working group. Livest. Prod. Sci. 49:1-21. http://dx.doi.org/10.1016/ S0301-6226(97)00041-9.

Hansen, P., and F. Ombler. 2009. A new method for scoring additive multi-attribute value models using pairwise rankings of alternatives. J. Multi-Crit. Decis. Anal. 15:87-107. http://dx.doi. org/10.1002/mcda.428.

Holm, S. 1979. A simple sequentially rejective multiple test procedure. Scand. J. Stat. 6:65-70.

Husson, F., J. Josse, and J. Pages. 2010. Principal component methods-Hierarchical clustering-Partitional clustering: Why would we need to choose for visualizing data. Applied Mathematics Department, AgroCampus Ouest, Rennes, France.

Kargo, M., J. F. Ettema, L. Hjortø, J. Pedersen, and S. Østergaard. 2015. Derivation of economic values for breeding goal traits in conventional and organic dairy production. Page 403 in Book of
Abstracts of the 66th Annual Meeting of the European Association for Animal Production, Warsaw, Poland. Vol. 21. Wageningen Academic Publishers, Wageningen, the Netherlands. http:// dx.doi.org/10.3920/978-90-8686-816-2

Kargo, M., L. Hjortø, M. Toivonen, J. A. Eriksson, G. P. Aamand, and J. Pedersen. 2014. Economic basis for the Nordic Total Merit Index. J. Dairy Sci. 97:7879-7888. http://dx.doi.org/10.3168/ jds.2013-7694.

Landbrug and Fødevarer. 2014. Dairy Statistics 2014. Accessed Sep. 15, 2016. http://www.agricultureandfood.dk/ /media/ lf/tal-og-analyser/aarsstatistikker/mejeristatistik/2014/ mejeristatistik-2014.pdf?la=da

Martin-Collado, D., T. J. Byrne, P. R. Amer, B. F. S. Santos, M. Axford, and J. E. Pryce. 2015. Analyzing the heterogeneity of farmers' preferences for improvements in dairy cow traits using farmer typologies. J. Dairy Sci. 98:4148-4161. http://dx.doi.org/10.3168/ jds.2014-9194.

Nielsen, H. M., and P. R. Amer. 2007. An approach to derive economic weights in breeding objectives using partial profile choice experiments. Animal 1:1254-1262. http://dx.doi.org/10.1017/ S1751731107000729

Nielsen, H. M., P. R. Amer, and T. J. Byrne. 2014. Approaches to formulating practical breeding objectives for animal production systems. Acta Agric. Scand. Anim. Sci. 64:2-12. http://dx.doi.org /10.1080/09064702.2013.827237.

Ouma, E., A. Abdulai, and A. Drucker. 2007. Measuring heterogeneous preferences for cattle traits among cattle-keeping households in East Africa. Am. J. Agric. Econ. 89:1005-1019. http://dx.doi. org $/ 10.1111 /$ j.1467-8276.2007.01022.x.

Pohlert, T. 2015. The Pairwise Multiple Comparison of Mean Ranks Package (PMCMR). Accessed Sep. 15, 2016. http://cran. ms.unimelb.edu.au/web/packages/PMCMR/vignettes/PMCMR. pdf.

Ragkos, A., and Z. Abas. 2015. Using the choice experiment method in the design of breeding goals in dairy sheep. Animal 9:208-217. http://dx.doi.org/10.1017/S1751731114002353

Rosati, A., and A. Aumaitre. 2004. Organic dairy farming in Europe. Livest. Prod. Sci. 90:41-51. http://dx.doi.org/10.1016/j. livprodsci.2004.07.005.

Sachs, L. 2013. Angewandte Statistik: Anwendung statistischer Methoden. Springer-Verlag, Berlin, Germany.

Slagboom, M. 2015. Internship report: Do breeding goals for organic and conventional dairy farming systems differ in Danish Holstein cattle? Aarhus University, Foulum, Denmark.

Sy, H. A., M. D. Faminow, G. V. Johnson, and G. Crow. 1997. Estimating the values of cattle characteristics using an ordered probit model. Am. J. Agric. Econ. 79:463-476. http://dx.doi. org $/ 10.2307 / 1244144$.

Tano, K., M. Kamuanga, M. D. Faminow, and B. Swallow. 2003. Using conjoint analysis to estimate farmer's preferences for cattle traits in West Africa. Ecol. Econ. 45:393-407. http://dx.doi. org/10.1016/S0921-8009(03)00093-4. 